\title{
Immunological parameters of dental alloy corrosion; A study of gingival inflammation after placement of Stainless Steel Crown
}

\author{
Ratna Indriyanti \\ Department of Pediatric Dentistry Faculty of Dentistry Universitas Padjadjaran
}

\begin{abstract}
\end{abstract}
Dental alloy is widely used in many field of dentistry as a restoration material, orthodontic, prosthodontic, oral surgery and endodontic treatments. Naturally, most of metallic materials without exception to stainless steel alloy will experience a process of corrosion in a form of electrochemical reaction to achieve thermodynamic equilibrium. The corrosion process in the oral cavity is due to reaction of metal with saliva as an oral cavity electrolyte fluid. SSC is preformed restoration material conform with dental anatomy, manufactured from stainless steel alloy which is formable and adaptable to the teeth. Stainless Steel Crown generally made of austenitic stainless steel 18/8 of AISI 304 group contain chrome $18 \%$ and Nickel $8 \%$, can be used as a restoration for teeth with excessive caries, crown fracture, email hypoplasia, or restoration after endodontic treatment. The toxic effect of $\mathrm{Ni}^{+2}$ released due to corrosion process may cause an inflammation on the gingiva and periodontal tissue. Laboratorically this condition indicated by the expression of pro-inflammation cytokines as immunological parameters such as IL-6, IL8 , TNFa and IL-1B whose main role is to initiate and enhance any inflammation responses. The presence of pro-inflammation cytokines can be detected as soon as 1 hour after placement of SSC by examination of gingival crevicular fluid (GCF) by ELISA technique. The magnitude of toxic effect is depends on corrosion rate and ions release which is influenced by metal chemical composition, environment temperature and $\mathrm{pH}$, metal wear due to abrasion and friction, soldering if any, and elongation of the metal. Conclusion: The release of $\mathrm{Ni}^{+2}$ during corrosion process after placement of SSC cause gingival inflammation which is indicated by the change of the immunological parameters.

Key words: Stainless Steel Crown, corrosion, inflammation, immunological parameter

\section{INTRODUCTION}

Stainless Steel Crown (SSC) is a non-corrosive dental alloy that can be used for temporary restoration or tooth anatomic fixed restoration. It is easy to manipulate and adapted to the tooth that has experienced wide damage caused by caries, crown fracture, enamel hypoplasia or as a restoration after nervous treatment.9,17

SSC is widely used in dentistry due to several considerations, i.e. easy manipulation, easily available, inexpensive and only needs few patient's visits leading to technical advantage for the operator and economical advantage for patients. ${ }^{9,17}$

SSC composition includes $18 \%$ chrome, 
$8 \%$ Nickel (referred as alloy 18-8) with a carbon content of $0.8-20 \% .11,20$. This alloy shows advantageous natures, i.e. the bigger the applied force, the harder the material. The high chrome content also will reduce corrosion. ${ }^{11,16}$

Just like other alloys, the dental alloy will experience corrosion in saliva as the oral electrolyte solution. ${ }^{4}$ Wear is an important factor that will make corrosion faster, especially due to the broken protective layer. ${ }^{16}$

Several researches show that metal restoration materials trigger local reactions in tissues such as oral gingivitis or periodontitis. ${ }^{1,10}$ The severity depends on the type of the metal and its content and chemical concentration. It is also reported that metal ion release can penetrate the hard tissue of the mouth. ${ }^{8,13}$

Research on IL-1B cytokine release as an inflammation marker after SSC application show that although clinically there is no change in the gingival condition, the increased IL-1B is seen up to the limit of mild inflammation. ${ }^{5}$

Certain alloy has been known as the cause of gingival and periodontal inflammation. However, there is only little information available to explain the role of molecules during the tissue inflammation process. SSC evaluation is quite hard in terms of technical, biological and clinical parts that leads to limited pertinent information. ${ }^{11}$

Currently, studies that support knowledge on non-corrosive stainless steel based restoration are still very much needed. Such studies are expected to support the opinion that SSC can be used as the restoration material of choice for pediatric patients.

\section{Overview of Stainless Steel Crown}

Stainless Steel Crown (SSC) is a non-corrosive stainless steel crown that is used for temporary restoration or filling for primary posterior teeth. The material has the form that is suitable with natural teeth and it can be easily manipulated to be adapted to the prepared dental surface. ${ }^{9,17}$

The indication of SSC use is tooth with wide caries, tooth that has enamel defect such as enamel hypoplasia and imperfect amelogenesis. SSC can also be used in teeth that has experienced fracture and for abutment teeth in space maintainer application..$^{9,17}$

The materials contains metal alloy with
$18 \%$ Chromium, $8 \%$ Nickel (referred as alloy $18-8$ ), with a carbon content of $0.8-20 \%$. SSC shows the following nature:9,14 (1) Heating will not increase strength; (2) The bigger the applied force, the harder the material; (3) High chrome content reduces corrosion; and (4) Soldering will reduce resistance towards corrosion.

SSC is different from cast gold and formed crown in the fact that SSC does not use precision fit and with the help of pliers and good clinical adaptation, SSC can be adapted to natural undercut. SSC has a spring effect that make it locked in the undercut after passing the biggest contour of the teeth. SSC resisting force is not dependent in nature because of the form and contouring. The studies show that the cementing media gives major contribution on SSC resistance. After examination, refine the SSC preparation because there is a tight relationship between crown misadaptation and gingivitis around the imperfect crown. Therefore, SSC should be adapted carefully. ${ }^{9,10}$

\section{Basic concept of inflammation}

Inflammation is a visible change of tissue due to vascular permeability change and dilatation that is often followed by leukocyte absorption to the affected tissue. This change causes erythema, edema, hot feeling, pain and function laesa that make up the signs of inflammation. ${ }^{3,12}$ Specifically, inflammation may happen in three types, i.e. immediate, acute and chronic. Leukocyte comes from bone marrow that will be released from the blood vessel through transendothelial migration in normal condition, e.g. resident leukocyte in tissues. ${ }^{3,6}$ The most important resident leukocytes are mast cells, peripheral dendritic cells, monocyte-derived cells such as dermal dendrocyte (histiocytes) and macrophage. Resident leukocyte sends information that start immediate inflammation. Immediate inflammation only takes several minutes before acute inflammation follows for a short period (in hours) characterized by neutrophil flow to the inflammation area after blood coming out from the area. If the problem has not disappeared, the acute inflammation gives way to a process which may never end, i.e. the chronic inflammation that is dominated by lymphocyte and macrophage migration to local tissues. Leukocytes sent to local 
tissues during acute and chronic inflammation is called inflammation leukocytes. ${ }^{3,8}$

\section{DISCUSSION}

\section{Overview of corrosion in dental alloy}

Non-corrosive steel alloy (stainless steel) experiences corrosion through electrochemical reactions. The metal alloy components will be oxidized in the form of ions while the diluted oxygen will be reduced into hydroxil ions. During the corrosion process, total oxidation reaction progress and reduction reaction progress should be the same.

The general form of corrosion reaction is as followed: ${ }^{7}$

Anodal reaction:

Metal $-\mathrm{e}^{-} \rightarrow \mathrm{M}^{+}$(called metal cation). Catodal reaction:

$1 / 2 \mathrm{O}_{2}+\mathrm{H}_{2} \mathrm{O}+2 \mathrm{e} \rightarrow 2 \mathrm{OH}^{-}$

The types of corrosion that may happen in the alloys used presently are crevice corrosion, galvanic corrosion, granular border corrosion, SCC (stress corrosion cracking), fatigue corrosion, and pitting corrosion. Pitting is a heavy form of local corrosion that creates wide damage and huge number of metal ion releases that leave small pores in the material surface. ${ }^{7}$ The corrosion and ion release level also depends on the metal composition, temperature, and environmental $\mathrm{pH}$, metal wear due to friction and abrasion, soldering, and applied strain. ${ }^{10,16}$

\section{Dental metal alloy in the mouth}

The disadvantageous effect of dental metal material is the presence of corrosion process that makes metal ions released. Corrosion is characterized by electrochemical reaction in metal phase limit that cause the metal ions to be released in the form of cations. ${ }^{4,5}$

The number and nature of released cations are varied, depends on the alloy type and other parameters, such as the type of corrosion, composition and electrolyte chemical nature such as $\mathrm{pH}$, ion composition, artificial saliva, serum, etc that also affects the cations..$^{9,15}$

Nickel based alloy shows meaningful corrosion and $\mathrm{Ni}$ ion release after it is kept in $\mathrm{pH}$ 1 or 4 , while the high noble alloy is not affected by low $\mathrm{pH}$. $\mathrm{Ni}$ and $\mathrm{Cr}$ containing alloy without berillium is more resistant to corrosion than those that contain berillium. ${ }^{6}$.

In in vivo condition, various biological factors produced by oral microorganism or food content may cause corrosion. Interaction among various metal restoration and individual factors affect corrosion in oral cavity very much. Furthermore, corrosion can be speed up by phagocytic cells such as neutrophil. Wear is another important factors that can speed up in vivo corrosion process, especially when the passive protecting layer is broken. So corrosion and wear can happen simultaneously in oral environment. ${ }^{6,15}$

The next research reported that the nickel content in saliva and serum increases significantly after permanent orthodontic restoration application. It is reported that a threshold concentration of $\pm 30 \mathrm{ppm}$ will probably enough to trigger cytotoxic response. ${ }^{2}$ However, it is also stated that nickel contact in oral cavity of insensitive people may induce tolerance towards Nickel. Nickel sensitization may increase due to mechanical irritation, oral mucosa injury that may happen in orthodontic treatment. ${ }^{2}$ Environmental temperature and exposure duration may also become a factor. Contact stomatitis lesion may be various and is clinically visible. ${ }^{4,6}$

Metal ion release cannot be predicted from the nobility of material or the general composition of the alloy. Each product should be evaluated individually to see the corrosive behavior and metal component release in various corrosive environment. ${ }^{6}$.

In vitro and in vivo metal component and alloy effects using immunological parameters

Metal ions will bring bad effects to local and systemic immune response in patients with cast metal filling because of the metal ion interactive effect with immunological parameters that have been studied in vitro and in vivo. ${ }^{11,14,20}$ The production of various immune mediator after metal material placement has been studied in lymphocyte cell line. The expression of inflammation mediator IL-2 and immune effector IgG by B cells and T cells is determined after incubation with three copper based cast alloys. The production of both immune mediators is changed by released cations. Artificial osteoblasts stimulated by LPS shows increased production of IL-1a, IL-6, IL-8 and TNF-a after 
being incubated by $\mathrm{Ti}, \mathrm{Cu}$, and $\mathrm{Cr}^{6}$

The concentration of circulated $\mathrm{T}$ lympocyte and other parameter such as hematocryte, difference in number of leukocytes and total leukocytes, saliva $\mathrm{Ni}$ concentration and serum $\mathrm{Ni}$ concentration etc. is determined during the period of 6 months after the patients received fixed partial prothetics made from $\mathrm{NiCr}$. There is no changes in $\mathrm{Ni}$ content level in saliva and serum found in this period. Although the monocyte and lymphocyte $T$ population is not changed, the number of circulated eosinophils is decreased and the population of neutrophils and basophils is increased.

Basophils play a role in hypersensitivity reaction so that hypersensitivity caused by metal ion released by $\mathrm{Ni}$ based alloy cannot be ignored. ${ }^{2}$ The derived metal components of dental cast filling can strenghten the expression of various immunological factors leading to its role in the etiology of various intraoral pathological condition. Increased cytokine expression after LPS stimulation in various cells show that bacterial toxins and factors related to materials such as released cations due to corrosion may produce additional or synergic inflammation effects in oral disease pathogenesis such as oral mucocytis, gingivitis/ periodontitis and alveolar bone resorption. ${ }^{1,11}$

Biocomptability of cast metal restoration is especially determined by the number and nature of released cations. Several researchers have reported that $\mathrm{Cu}, \mathrm{Ni}$ and $\mathrm{Be}$ have a clear cytotoxic potentials. In vitro research shows that various metal elements such as $\mathrm{Ni}$, Co and $\mathrm{Cr}$ can strengthen immune responses. In vivo effects of those metals to the immune response are not known yet. ${ }^{4}$

Various other factors can support metal filling biological interaction such as physicochemistry surface parameters (atomic comparison between noble metal and non noble metal), phase formation, wear and the quality of the manufacturing process itself. ${ }^{16}$

\section{CONCLUSION}

The $\mathrm{Ni}^{+2}$ component release in corrosion after SSC application creates gingival inflammation characterized by the presence of various immunological parameters.

\section{SUGGESTION}

To avoid a situation where the corrosion process in Nickel and Chrome based SSC restoration materials produce severe tissue damage effect, several things should be attended including the metal alloy composition, good SSC management by operator and information to patients to regulate his/her eating pattern such as reducing sour food. Eliminate bad habit that may cause metal restoration damages in oral cavity. It is also recommended to do routine visit to dentist.

\section{REFERENCES}

1. Bailey LO, Lippiatt S, Biancanello FS, Ridder SD, Washburn NR. The quantification of cellular viability and inflammatory response to stainless steel. J Biomaterial 2005;26(26):5296-302.

2. Bass JK, Fine H, Cisneros GJ. Nickel hypersensitivity in the orthodontic patient. Am J Orthod Dentofac Orthop 1993;103:280-5.

3. Carranza FA. Glickman's clinical periodontology. Philadelphia: W.B. Saunders; 2006. p. 209-27.

4. Geurtsen W. Biocompatibility of dental casting alloys. Critical Rev of Oral Biol Med 2002;13(1):71-4.

5. Indriyanti R. Kadar interleukin1-beta pada GCF setelah pemasangan SSC pada gigi sulung; Peninjauan secara klinis dan laboratoris. Tesis. Bandung: Bagian Ilmu Kedokteran Gigi Anak FKG UNPAD; 2006. p. 28-34, 51-62.

6. Janeway CA, Travers P, Walport M, Shlomchik MJ. Immunobiology: the immune system in health and disease. $6^{\text {th }}$ ed. New York: Garland Science; 2005. p. 1-37.

7. Jones DA. Principles and prevention of corrosion. London: Mac Millan Publishing Co.; 2001. p. 4-21.

8. Knoernchild KL, Campbell SD. Periodontal tissue responses after insertion of artificial crowns and fixed partial dentures. J Prosthet Dent 2000;84(5):492-8.

9. Mathewson RJ, Primosch RE. Fundamentals of pediatric dentistry. $3^{\text {rd }}$ ed. Chicago Quintenssence Publishing Co. Inc.; 1995:233246.

10. MatWeb Material Property Data The online materials database. 2006. [cited 2006 Jun 26] 
Available from:<http://www.matweb.com >.

11. Özen J. The effect of fixed restoration materials on the IL-1 B content of gingival crevicular fluid. Turk J Med Sci 2001;31:36569

12. Roeslan BO. Imunologi oral: kelainan pada rongga mulut. Jakarta: Balai Penerbit Fakultas Kedokteran Universitas Indonesia; 2002. p. 38,44-81,161-82.

13. Schmalz G. Biological interactions of dental cast alloys with oral tissue. Trans Acad Dent Mater 1999;13:97-114.
14. Smith WF. Structure and properties of engineering alloys. $2^{\text {nd }}$ ed. New York: McGrawHill Inc.; 1993. p. 312-22.

15. Stites D, Terr Al, Parslow TG. Medical immunology. $9^{\text {th }}$ ed. London: Prentice Hall Int. Inc.; 2001. p. 63-73, 146-68, 182-210.

16. Traisnel M, Le Maguer D, Hildebrand HF, lost A. Corosion of surgical implant. Clin Material 1990;5:309-8.

17. Wellburry RR. Paediatric dentistry. $2^{\text {nd }}$ ed. New York: Oxford Univ Press Inc.; 2001. p. 129-48. 